\title{
MODELO GEOMÉTRICO Y ARQUITECTÓNICO DE LA CÚPULA MAYOR EN SAN JOSÉ DE CÚCUTA
}

\section{GEOMETRIC AND ARCHITECTUR- AL MODELO OF THE MAIN DOME IN SAN JOSÉ DE CÚCUTA}

Yannette Díaz Umaña',

\section{Mawency Vergel Ortega ${ }^{2}$}

\section{Julio Delgado³}

Universidad Francisco de Paula Santander

\section{RESUMEN}

El objetivo principal del escrito basado en la investigación de la Catedral de San José de 1 Yannette Díaz Umaña Docente titular de la Universidad Francisco de Paula Santander, pertenece al grupo de investigación TARGET del Departamento de Arquitectura. yannettedu@ufps.edu.co Http://orcid. Org/0000-00034582-1593

2 Mawency Vergel-Ortega Docente titular de la Universidad Francisco de Paula Santander, pertenece al grupo de investigación EULER del Departamento de matemáticas. mawency@ufps.edu.co, https://orcid.org/0000-0001-8285$\underline{2968}$

3 Julio Alfredo Delgado Docente de la Universidad Francisco de Paula Santander, pertenece al grupo de investigación SIMO del Departamento de matemáticas. julioalfredodelgado@hotmail.com

https://orcid.org/0000-0001-6944-832X
Cúcuta, ubicada en el Norte de Santander, es determinar las características simbólicas, arquitectónicas y geométricas de la cúpula, teniendo en cuenta la memoria documental, comparándola con los datos obtenidos en sitio, de frente a favorecer la construcción de un estudio descriptivo de este templo de estilo neoclásico, hito histórico y cultural en la ciudad de Cúcuta.

PALABRAS CLAVE: Cúpula, técnica constructiva, arquitectura, simbolismo. 


\section{SUMMARY}

The main objective of the paper based on the investigation of the Cathedral of San José de Cúcuta, located in the North of Santander, is to determine the symbolic, architectural and geometric characteristics of the dome, taking into account the documentary memory, comparing it with the data obtained on site, to favor the construction of a descriptive study of this neoclassical style temple, historical and cultural landmark in the city of Cúcuta.

KEYWORDS: Dome, construction technique, architecture, symbolism.

\section{LA CÚPULA MAYOR UN MODELO HISTÓRICO}

Para empezar, "Modelo geométrico y arquitectónico de la cúpula mayor en San José de Cúcuta", está referido a la construcción más emblemática de la Iglesia católica de esta ciudad, según Delgado Diaz, \& Vergel (2.018). Uno de los elementos más icónicos de la catedral es su cúpula semiesférica, dado que al exterior resalta sobre el paisaje urbano con su forma poco convencional, $y$ al interior despliega toda su belleza espacial y fenomenológica con la que logra ser un punto articulador de toda la construcción.
De igual forma, la copula configura un skyline curvilíneo atípico, pues se contrapone a las superficies rectilíneas de los perfiles constructivos que predominan en la ciudad (imagen 1). Especialmente en la actualidad, donde adquiere por contraste un fuerte misticismo. En este sentido Baeza (2014) comenta el valor histórico y cultural de la cúpula, debido a múltiples razones, por ejemplo, su ingenio al procurar la sensación de ingravidez y por sus orígenes multiculturales por lo que expresa:

"Tal es el caso de las espléndidas cúpulas de las mezquitas bizantinas que recortan el cielo brumoso de Estambul. $\mathrm{O}$ el inconfundible perfil de la Cúpula de la Roca, con su brillante piel de láminas de cobre pulido, que domina, desde cualquier punto de vista, la "Ciudad Santa" de Jerusalén.

Sin olvidar la majestuosa cúpula que hizo Miguel Ángel para la basílica de San Pedro de Roma inspirada, a su vez, en la de la catedral Toscana con la que Bruneleschi sorprendiera a toda la cristiandad con sus desafiantes dimensiones." (Baeza, 2014: 80)

Aunado a esto, el valor simbólico, que este autor le confiere, al dotar al edificio de un carácter sagrado vinculando su significado cosmológico al representar la "bóveda celeste".

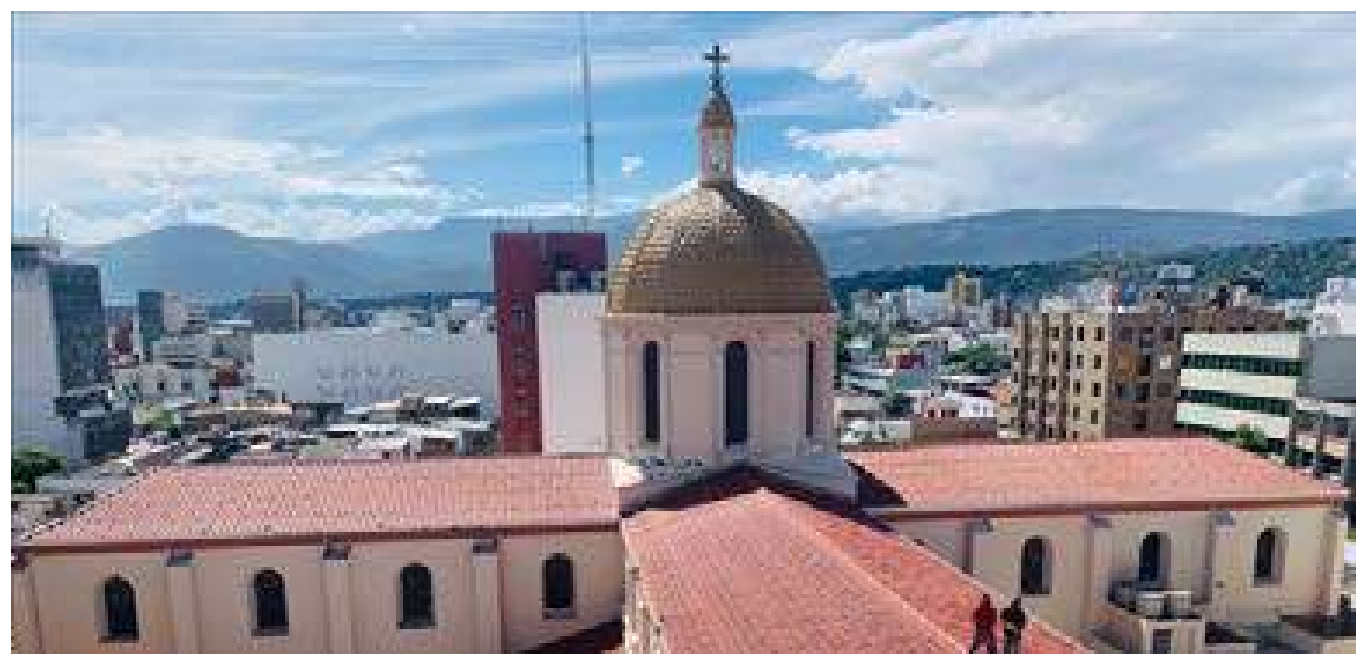

Imagen 1. Vista de la cúpula y entorno construido. 
Algo semejante ocurre con Llonch \& Gurrea (1996) cuando relacionan el poder simbólico de la cúpula, por su posible origen, relacionando varias culturas como los caldeos y asirios, persas sasánidas, romanos y bizantinos en sus inicios, así que deja abierta la posibilidad a una hipótesis que establece su comienzo en Oriente o en Occidente, dejando claro, que ante la imposibilidad de dar tal precisión sobre su comienzo, lo importante es destacar, que la transmisión de la técnica constructiva de la cúpula, alcanzó una alta calidad arquitectónica, precisamente por la participación multicultural y su adquisición paulatina y transmitida a lo largo del tiempo aplicada a las diferentes técnicas de ejecución.

\section{ARQUITECTURA Y GEOMETRÍA DE LA CÚPULA MAYOR.}

Estas apreciaciones son pertinentes como preámbulo a las condiciones particulares de la cúpula de la Catedral de San José de Cúcuta, elevada encima del cimborrio, apoyado en las pechinas que, a su vez, se afirman sobre los arcos torales, dispuestos en una base cuadrada delineada por el crucero. En la cúpula se destaca su extradós semiesférico revestido con hojas traslapadas en concreto. Esta solución constructiva permite compatibilizar la geometría de la cúpula con las nervaduras integradas. Sobre ella, se encuentra la linterna conformada por ocho vanos enmarcados por pilastras de fuste liso, en su parte superior se ubica un capulín, de características similares a la cúpula, pero en menores proporciones, finalmente el remate es logrado en la parte más alta, con la bola y la cruz a una altura de $35 \mathrm{~m}$ sobre el nivel del suelo (imagen 2). Para Rivas (2008) la cúpula constituye un elemento protagónico por su elevada posición y su remate compositivo de toda la edificación.
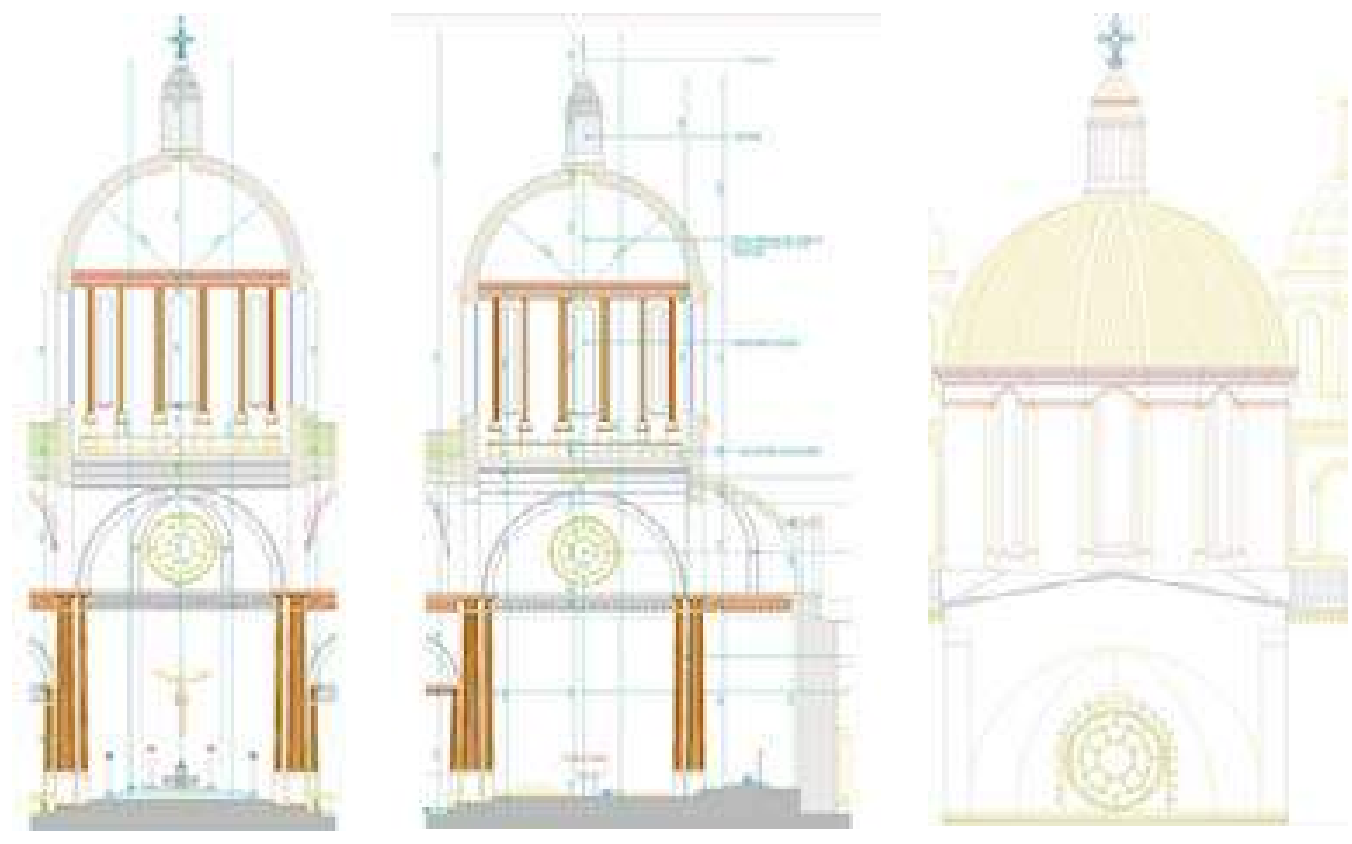

Imagen 2. Corte trasversal crucero sobre nave central, Corte trasversal crucero sobre transepto, fachada cimborrio con ábside de la Catedral de San José de Cúcuta. 
En otro sentido, la atención lograda por la cúpula, en la arquitectura Sagrada, sobrepasa su premisa compositiva, definida por la intersección de la nave central y el transepto, a una altura aproximada de $23 \mathrm{~m}$ sobre el altar. Esta practica estilística se ve relacionada con la intensión litúrgica, ya que ambas tienen como punto de referencia el altar. Esta ubicación de la zona presbiteral, en el centro de la iglesia, fue motivada por las reformas preconciliares cuya intención era la participación de los fieles en la liturgia, tal como lo narra (Díaz 2019), tras una ubicación más alejada en el ábside, como era la práctica antigua y medieval.

Por su parte Rosenthal (2011), haciendo alusión a esta circunstancia, habla de la democratización, de la redención de la intimidad de la celebración de la misa paleocristiana, y de estar unidos en torno al altar, en el centro cupuliforme de la iglesia. Este mismo autor subraya que los ejemplos de esta disposición espacial del altar centralizado bajo la cúpula, se ven singularmente en esquemas de forma de cruz latina, tal como se evidencia en la Catedral. Debido a estas concepciones es prudente afirmar que la cúpula trasciende en su papel estético de criterios meramente ornamentales para seguir pautas fundadas en el simbolismo.

Con esta configuración, interiormente se dispone un espacio fenomenológico, en donde la cúpula como centro de la catedral, esta sostenida por los cuatro arcos torales, esta estructura permite que la cúpula parezca estar suspendida en el aire, apoyando la sensación de ingravidez y representando el mismo cielo. No obstante, la disposición espacial interna del crucero, va más allá, al revelar una jerarquía ascendente que insiste en revelar su valor simbólico.

En esta medida se encuentran las pechinas que descansan sobre los arcos torales, las cuales hacen alegoría cada una de ellas a la tradición, el evangelio, la Santa Madre de Dios y la Eucaristía, como base de la iglesia católica. En segunda medida, un conjunto de santos, mártires y ángeles, representados en sus ocho vitrales que rodean tambor con $6.67 \mathrm{~m}$ de alto. Y la última jerarquía, que acentúa su valor fenomenológico, por cuanto la impresión visual es estimulada por la ornamentación pictórica del intradós de la cúpula, desarrollada en un espacio de $9.80 \mathrm{~m}$ de diámetro por una alzada de $6.08 \mathrm{~m}$ recreando al Padre Celestial, Jesús, San José a su llegada al cielo y los serafines acompañando toda la composición celestial. (imagen3).

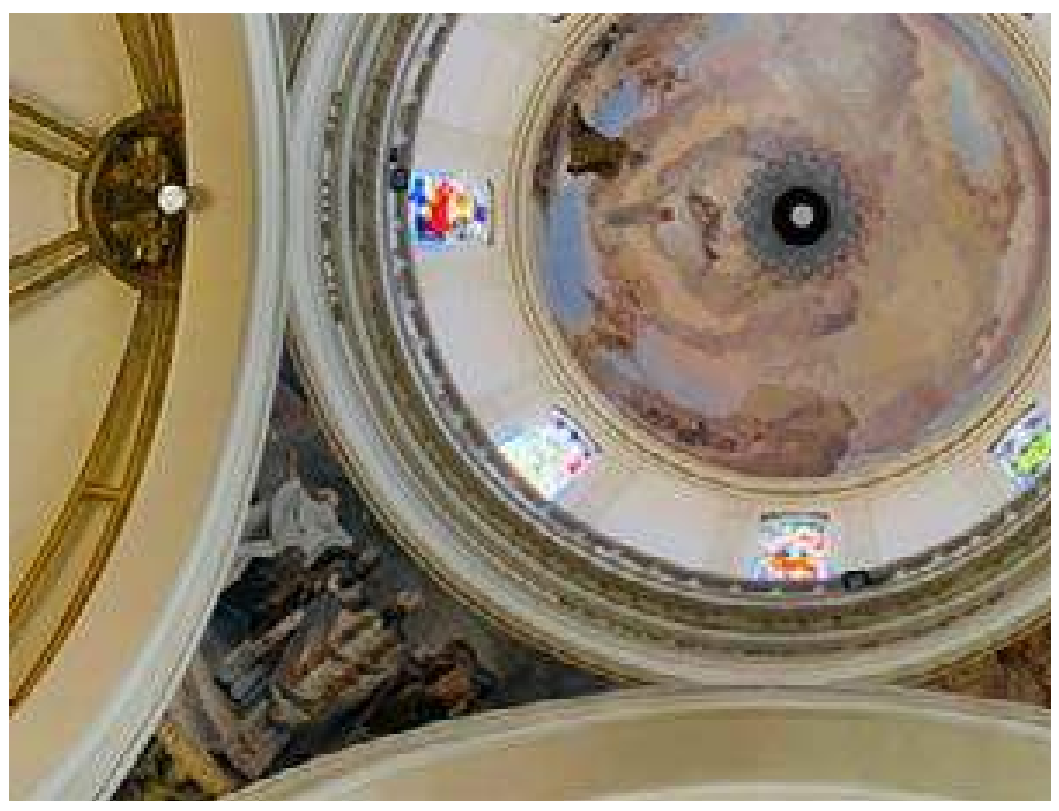

Imagen 3. Vista del intradós, tambor y pechinas desde el altar. 
De esta forma la jerarquización ascendente presenta de alguna manera el camino a Dios, es decir a la salvación. Ahora bien, el arte plasmado en la estructura de la cúpula, cumple su papel pedagógico y didáctico, al que se complementa de forma magistral el juego de la luz, pues al penetrar por el óculo y los vitrales del tambor, en las diferentes horas del día, se entre cruzan los haces lumínicos, a diferentes alturas revelando sobre las superficies internas, la incidencia del sol. Para Marín (2001), haciendo referencia a la cúpula de catedral de Edessa describe:

"El fiel que entra a la iglesia se sentirá sobrecogido por la iluminación y, al levantar la vista y dirigirla a la parte más alta, se encontrará con un cielo estrellado y, al final, el Pantocrátor, quedando inmóvil, perdido en el seno de esta inmensidad, sumergido por el infinito en el corazón de este espacio ilimitado, deslumbrado por la luz, material y mística, que irradia la cúpula" (Marín, 2001: 161)

el autor se refiere a este fenómeno como un arte sublime, pues se dispone gracias a la articulación de todos los recursos técnicos y estilísticos para conmover el alma del visitante hacia Dios, extasiándolo con el juego de colores, representaciones y haces luminosos (imagen4).
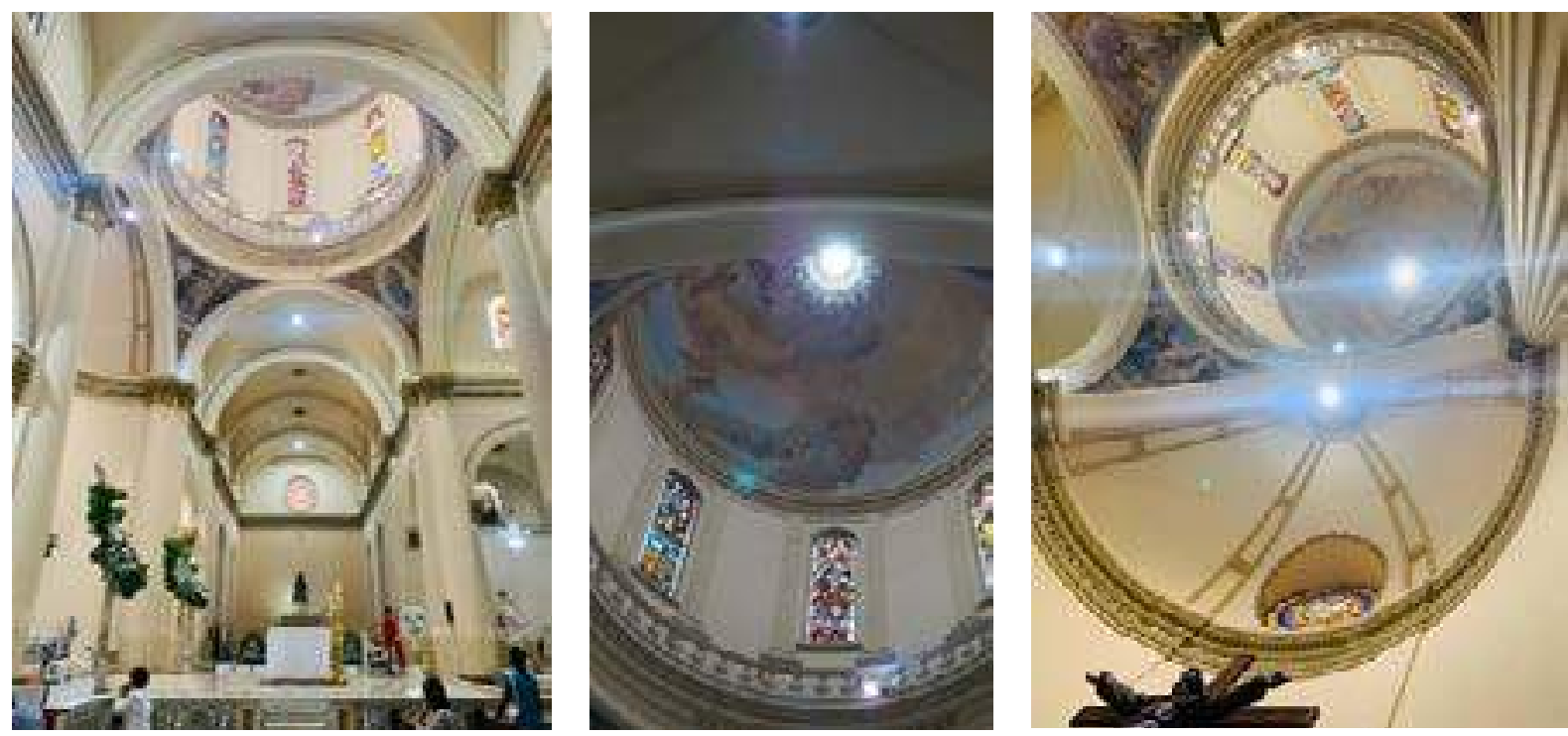

Imagen 4. Vista del altar arcos torales, pechinas, tambor, intradós y óculo con efectos lumínicos.

En cuanto la descripción constructiva de la cúpula, se puede determinar que su soltura geométrica se desprende de su centro con 16 nervaduras radiales que configuran su trazado circular, para Aliberti (2013) las cúpulas tienen generalmente una abertura cenital $u$ óculo con fines lumínicos y constructivos ya que facilitan el cierre de la estructura. Esta abertura se encuentra generalmente en una proporción que oscila entre $1 / 4$ y $1 / 6$ sostiene Aliberti (2013).

Estas observaciones se relacionan con los $9.80 \mathrm{~m}$ de diámetro de la planta, la altura de
$6.08 \mathrm{~m}$, lo cual precisa una proporción de 1/16. En este aspecto Aliberti (2013) y Huerta (2004) indican que, aunque el espesor de las cupulas es variado la relación existente con su diámetro oscila entre $1 / 9$ y $1 / 42$, siendo en la mayoría de los casos entre 1/16 y 1/22 con una media general de 1/20. La manufactura de ladrillo de la cúpula, supone entre 40 y $50 \mathrm{Kg} / \mathrm{cm} 2$ de resistencia a la compresión y entre 2 y $5 \mathrm{KG} /$ cm2 de resistencia a la tracción. Con estas aproximaciones Martínez \& Alonso (2003), explican que la caracterización de este material es su baja capacidad para desarrollar tensiones 
de tracción, con respecto a una buena resistencia a la compresión. Esto condiciona su estabilidad, que depende de su forma y dimensión, es decir, son estructuras que resisten por su forma más que por la resistencia del material, siempre que éste mantenga sus propiedades mecánicas tal como lo afirman estos autores (imagen 5).
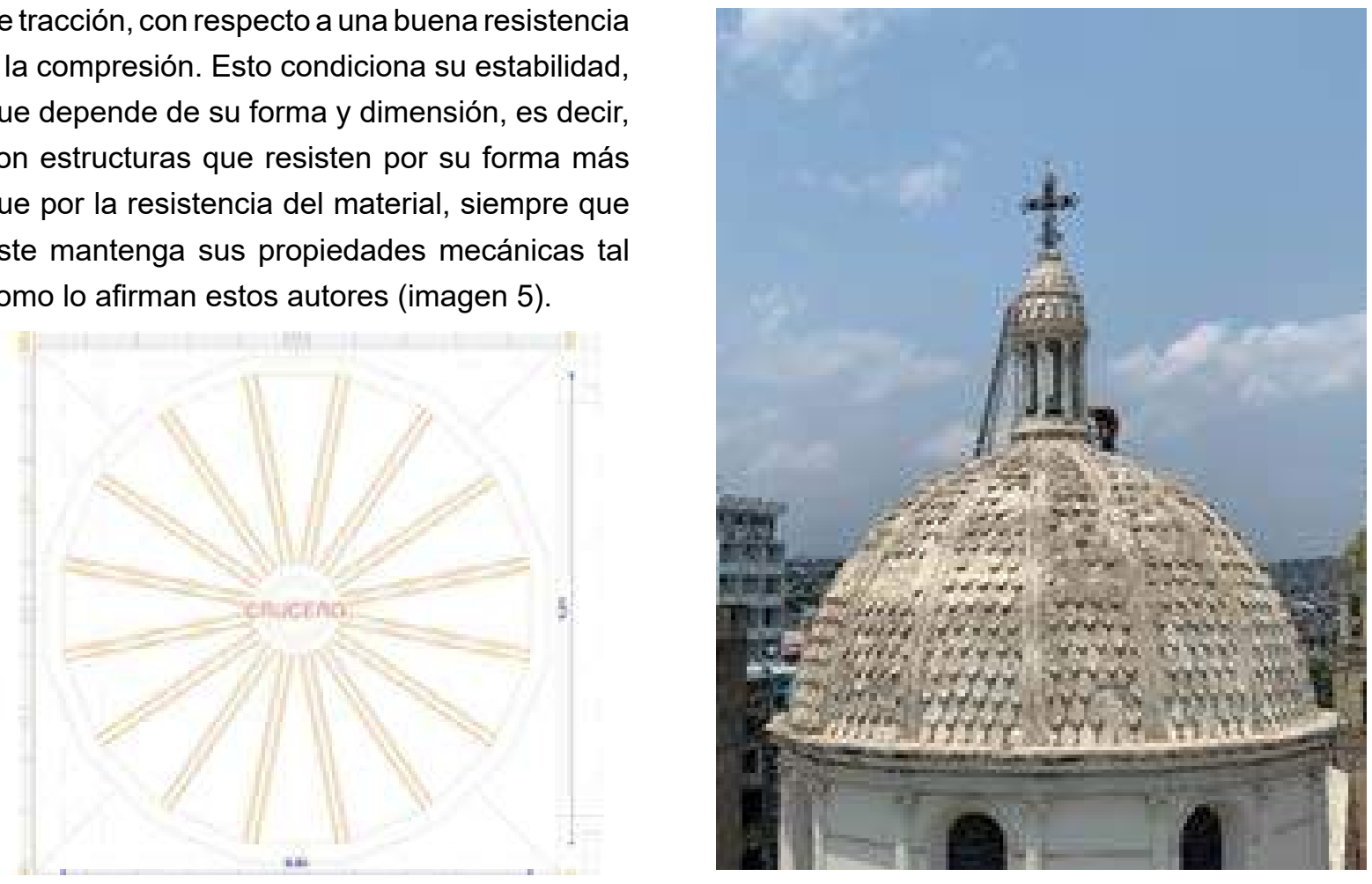

Imagen 5. Planta e imagen del extradós de la cúpula.

\section{CONCLUSIONES}

En ultimas la cúpula de la catedral de San José de Cúcuta configura un skyline curvilíneo místico con un valor simbólico, vinculando su significado cosmológico al representar la "bóveda celeste", esta representación del cielo, entre otras es lograda por sus características que le confieren una propiedad de ingravidez. Aunado a esto, el arte plasmado en el intradós de la cúpula, cumple su misión pedagógica y didáctica, en la que intervienen los haces lumínicos que penetran por el óculo y los vitrales del tambor, al ascender y descender el sol, esto cobra un interesante juego lumínico al interior del crucero.

Como se ha mostrado, la cúpula trasciende del tema estético y ornamental para fundamentarse en el simbolismo, esto se explica con la ubicación de la zona presbiteral, en el centro de la iglesia, cambio inspirado en reformas preconciliares cuya intención era la participación de los fieles en la liturgia, de allí lograr una mayor conexión del creyente con la celebración eucarística. En efecto, esta localización del altar en el centro, se ve singularmente en esquemas de forma de cruz latina, tal como se evidencia en la Catedral.

También se destaca la técnica constructiva de la cúpula, en cuanto a sus orígenes, poco precisos, pero con un alto valor cultural, pues la transmisión de la técnica constructiva de la cúpula, alcanzó una alta calidad arquitectónica, precisamente por la participación multicultural y su adquisición paulatina y transmitida a lo largo del tiempo, trabajada con diferentes técnicas.

Por lo tanto, se resalta su técnica constructiva elaborada en manufactura de ladrillo, explicando su baja capacidad para desarrollar tensiones de tracción, con respecto a una muy buena resistencia a la compresión. Esto determina su firmeza, que estriba de su forma y dimensión, más que por la resistencia del material. No obstante, este, debe conservar sus propiedades mecánicas. 


\section{REFERENCIAS BIBLIOGRÁFICAS}

Aliberti, L. (2013). "Cúpulas clásicas romanas: Geometría y construcción" en Actas del Octavo Congreso Nacional de Historia de la Construcción. Madrid, 9-12 de octubre de 2013. Madrid: Instituto Juan de Herrera. Disponible en internet: http://www.sedhc.es/biblioteca/acta. php?id_act=10\&id_cng=11 Consultado el 4 de julio de 2019

Delgado, A., Diaz, Y. \& Vergel, M. (2.018). El paisaje Arquitectónico y sonoro del campanario de la Catedral de San José de Cúcuta. Revista Logos Ciencia \& Tecnología.vol.11 N 1, enero marzo 2.019 P52-60v

Díaz, Y. (2019). La arquitectura sagrada en San José de Cúcuta (I Parte ): Caso de estudio, Iglesia de Nuestra Señora de la Candelaria. Trabajo investigativo presentado para el escalafón docente. UFPS, Cúcuta, Colombia.

Baeza, C. (2014). La ciudad de las cúpulas. Akros, RevistadePatrimonio, $n^{\circ} 13$, pag 75-82Disponible en internet: file:///C:/Users/Dell/Downloads/ Dialnet-LaCiudadDeLasCupulas-4943195.pdf Consultado el 25 de junio de 2019

Huerta, S. (2004). Arcos, bóvedas y cúpulas. Geometría y equilibrio en el cálculo tradicional de estructuras de fábrica. Instituto Juan de Herrera, Escuela Técnica Superior de Arquitectura. Madrid Disponible en internet: http://oa.upm. es/1136/1/Huerta_2004_Arcos_bovedas_y cupulas.pdf? Consultado el 23 de junio de 2019

Llonch, J, \& Gurrea, A.( 1996). "Hipótesis sobre el origen de las cúpulas nervadas y caladas de la arquitectura hispano-musulmana" en Actas del Primer Congreso Nacional de Historia de la Construcción, Madrid, 19-21 septiembre 1996, eds. A. de las Casas, S. Huerta, E. Rabasa, Madrid: I. Juan de Herrera, CEHOPU.

Marín, J. (2001). Apuntes en torno al simbolismo de la arquitectura cupulada bizantina. Byzantion
Nea Hellás, 19-20, 2000-2001 pág. 142.165. Disponible en internet: file:///C:/Users/Dell/Dow nloads/37858-1-130387-1-10-20151203\%20(1). pdf Consultado el 29 de junio de 2019

Martínez, A. \& Alonso; A. (2003). Técnicas de diagnóstico estructural en construcciones historicas Análisis de la cúpula de San Miguel de los Reyes (Valencia). LOGGIA N¹4-15, pag162-171. Disponible en internet: file:///C:/ Users/Dell/Downloads/3564-11161-1-SM.pdf Consultado el 29 de julio de 2019

Moreno A and Gómez C.A. (2017). System1 helps keep operation in turboexpander at fcc plant. Orbit 117.

Rivas, J. (2008). Las iglesias barrocas de la ciudad de Murcia: consideraciones sobre su significación y arquitectura. IMAFRONTE N. ${ }^{\circ}$ 19-20 -2007-2008. Págs. 395-410. Disponible en internet: https://digitum.um.es/digitum/ bitstream/10201/12384/1/19.-\%20Rivas\%20

Rosenthal, E. (2011). La catedral de Granada: el altar mayor bajo cúpula en Anuario del Departamento de Historia y Teoría del Arte vol. 23, 2011, pp. 21-30 ISSN. 1130-5517 Disponible en internet: https://repositorio.uam.es/bitstream/ handle/10486/7830/43383_2.pdf?sequence $=1$ Consultado el 5 de agosto de 2019

Vergel-Ortega, M., Martínez Lozano, J., \& Contreras Díaz, M. (2016). Percepciones y características del espacio público y ambiente urbano entre habitantes de la ciudad de CúcutaColombia. Prospectiva. Revista de Trabajo Social e intervención social No. 21 abril 2016: pp. 213-239

Vergel Ortega, M y Paz Montes, L (2018) Ejes estratégicos y perfil del estudiante de matemática financiera de la Universidad Francisco de Paula Santander», Aibi revista investig. adm. ing., vol. $6,{ }^{\circ} 2$, pp. $33-38$ 